原 著

\title{
放射線画像系における確率的行列論と周波数解析論との接点
}

\author{
国立循環器病センター放射線䛦療部 \\ 若松孝司 \\ （論文受理 1984年 1 月18日） \\ （最終論文受理 1984年4月20日）
}

(Code No. 21120)

Key words: Probability matrix, Frequency analysis, Spectral signal-to-noise ratio, Detectivity, Whitening noise filter.

\section{THE JOINT BETWEEN PROBABILITY MATRIX AND FREQUENCY ANALYSIS THEORY FOR ESTIMATING THE IMAGE QUALITY OF A RADIOGRAPHIC IMAGING SYSTEM}

\section{TAKASHI WAKAMATSU}

National Cardiovascular Center Department of Radiology

(Article received; Jan., 18, 1984.)

\section{Summary}

In this paper, an estimation was made of the image quality of the radiographic imaging system, the joint between probability matrix and frequency analysis theory was made clear with mediating the idea of the whitening noise filter.

The detectivity $d^{\prime}$ of the ideal detector is defined as,

$$
\sqrt{\boldsymbol{S}_{1}^{T} \bar{\Phi}_{n n}^{-1} \overline{\boldsymbol{S}}_{1}}=\sqrt{\int_{-\infty}^{\infty} S_{1}(u)^{2} / W(u) d u}
$$

Where $S_{1}$ denotes the signal matrix, $\Phi_{n n}^{-1}$ the variance and co-variance inverse matrix, $S(u)$, the signal spectrum and $W(u)$, the Wiener spectrum of noise.

The next fomula used was,

$$
\Phi_{n n}^{-1}=G^{T} G
$$

Where $\boldsymbol{G}$ is the triangular matrix of the whitening noise filter.

$\boldsymbol{G}$ corresponds to $\sqrt{W(u)^{-1}}$ and $\boldsymbol{G} \boldsymbol{S}_{1}$ to the convolution between the whitening noise filter function on the spatial area and the signal distribution.

Thus, $\Phi_{n n}$ can be represented by a non singular and symmetric matrix whose normal diagonal elements are all same, and $\boldsymbol{G}$ can be represented by a triangular matrix whose normal diagonal elements are all same.

This proved that the noise process of the radiographic imaging system is a necessary ergodic. 


\section{1. 緒言}

放射線画像の画質の総合評洒において，最も客観的な 一つの方法は，人の視覚による ROC 曲線を求めること であった。その根底になるものは，心理物理学からの応 用としての確率および統計の理論である.したがって， 物理量をもとにした総合画像評価の理諭を構筑するに当 って，放射線画像論の中に確率および統計諭の击入は必 然的なものとなる1).しかも，確率および統計の理論の 導入が，人の視覚によるROC 曲線の結果を説明できる 可能性をもつ洼かりでなく，さらに徒来の周波数解析の 理論とも矛盾なく接合され得る形のものでなければなら な(21)2)4).

確率論の屡開には，信号扝よび雑音の空間領域でのデ シタル化が必要であり，乙れはサンプリングの定理によ って保証されている。

統計論の展開としては, デジタル化されたサンプル值 をもとにした，多変量正規分布密度関数の信号および杂隹 音の尤度比の刘数方程式の解を求めるために行列論の導 入が必要であり1)，乙れは放射線画像系における雑音の 架間的なエルゴード性 ${ }^{5}$ によって保証され得るものであ る.

以上の観点から著者らは，信号ベクトルを $S_{1}$ とし， 粒状雑音の共分散行列を $\Phi_{n n}$ とすると理想的検出器によ る検出能，すなうち系の $\mathrm{S} / \mathrm{N}$ 比の最大值は， $\sqrt{S_{1} T \mathscr{\Phi}_{n n}^{-1} \boldsymbol{S}_{1}}$ であるととを導出した。 ととるで， $\Phi_{n n}^{-1}=\boldsymbol{G}^{T} \boldsymbol{G}(\boldsymbol{G}$ ば三 角行列）となるので, $S_{1}^{T} \Phi_{n n}^{-1} S_{1}=\left(G S_{1}\right)^{T}\left(G S_{1}\right)$ と表わさ れるので, $\boldsymbol{G}$ は白色化雑音フィルタの作用を屯つ行列で あるととが判明しだ1.

放射線画像系では，粒状雑音のウィナースペクトル $W$ (u) が求められるので, 空間周波数領域における白色化 雑音フィルタは $W(u)^{-1 / 2}$ の形で表わされる.

したがって,

$$
\boldsymbol{S}_{1} T \boldsymbol{\Phi}_{n n}^{-1} \boldsymbol{S}_{1}=\int_{-\infty}^{\infty} \frac{S_{1}(u)^{2}}{W(u)} d u
$$

なる関係式が導出された。この関係式は,さらにMatched フィルタ論によって保証されている.との稿で問題にす るととは，既に $\boldsymbol{G}$ が三角行列であることの存在と証明が なされているので3，GS が何を意味し，何に刘応する のかを数学的な立場から直接的に明らかにする必要があ る. これによって, 行列論と周波数解析論の接点か明確 になるものと考えられる。
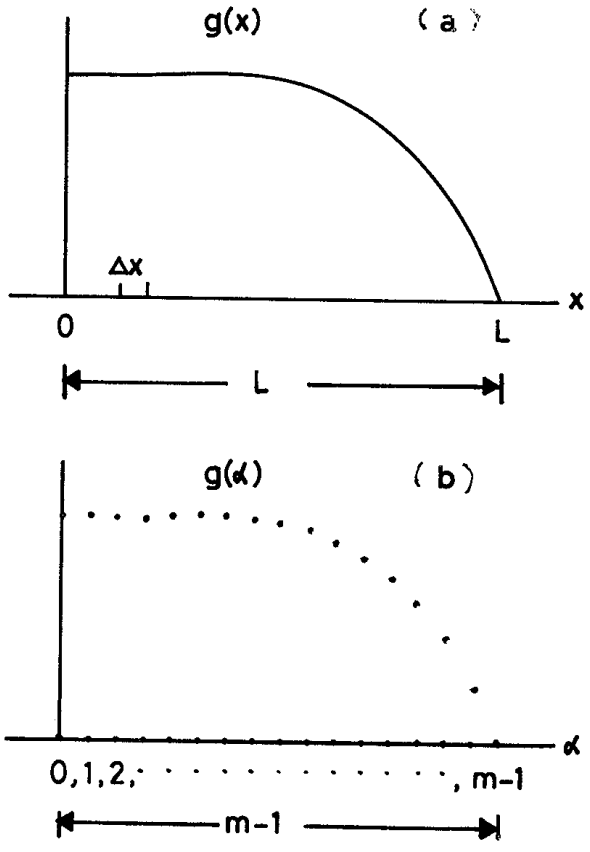

Sampling Points: $m$

Fig. 1. a: Distribution function $g(x)$ on the spatial area.

$\mathrm{b}$ : Discreting the distribution function $g(x)$ to the $x$ axis.

Fig. 1a のように, 距離 $x$ に対する分布関数 $g(x)$ があ り，系によって決められるナイキスト周波数に対応する サンプル間隔 $\Delta x$ ， そして分布関数の継続する領域 $L$ に 対応するサンプル点数 $m$ に離散化されたものを Fig. 1b とすると次式が得られる。

$$
g(x)=\sum_{\alpha=0}^{m-1} g(\alpha \Delta x) \frac{\sin ((\pi / \Delta x)(x-\alpha \Delta x))}{(\pi / \Delta x)(x-\alpha \Delta x)} \cdots \cdots(1)
$$

(1)式において, $g(\alpha \Delta x)=g(\alpha)$ と表示するととにする. 但し $\alpha$ は, $0 \sim m-1$ の整数.

他の分布関数 $S_{1}(x)$ についても同様なととが言える.

$g(x)$ と $S_{1}(x)$ の重畳積分 $C(x)$ は次式によって与えら れる。

$$
C(x)=\int_{-\infty}^{\infty} g(x-z) S_{1}(z) d z
$$

(2)式に対応する離散関数 $C(\alpha)$ は次式によって表わさ れる。

$$
C(\alpha)=\sum_{\beta=0}^{m-1} g(\alpha-\beta) S_{1}(\beta)
$$

(3)式において，一つの $\alpha$ の值に対して， $\beta$ を 0 から $m$ -1まで変化さすことによって $C(\alpha)$ の全体の值が決定 されることになる。

$\alpha=0$ のとき.

$\beta=0$ とおいて, 


$$
\begin{aligned}
& \left\{\begin{array}{l}
g(\alpha-\beta)=g(0) \\
S_{1}(\beta)=S_{1}(0)
\end{array}\right. \\
& \beta=1 \text { とおいて, } \\
& \left\{\begin{array}{l}
g(\alpha-\beta)=g(-1)=0(\because \text { 領域外 }) \\
S_{1}(\beta)=S_{1}(1)
\end{array}\right. \\
& \beta=2 \text { とおいて, } \\
& \left\{\begin{array}{l}
g(\alpha-\beta)=g(-2)=0 \\
S_{1}(\beta)=S_{1}(2)
\end{array}\right. \\
& \vdots \\
& \beta=m-1 \text { とおりて, } \\
& \left\{\begin{array}{l}
g(\alpha-\beta)=g(-m+1)=0 \\
S_{1}(\beta)=S_{1}(m-1)
\end{array}\right. \\
& \text { したがって， } \\
& C(1)=g(0) S_{1}(0)+0 \cdot S_{2}(0)+\cdots \cdots+0 \cdot S_{1}(m-1) \\
& \alpha=1 \text { のとき. } \\
& \beta=0 \text { とおいて, } \\
& \left\{\begin{array}{l}
g(\alpha-\beta)=g(1) \\
S_{1}(\beta)=S_{1}(0)
\end{array}\right. \\
& \beta=1 \text { とおいて, } \\
& \left\{\begin{array}{l}
g(\alpha-\beta)=g(0) \\
S_{1}(\beta)=S_{1}(1)
\end{array}\right. \\
& \beta=2 \text { とおいて, } \\
& \left\{\begin{array}{l}
g(\alpha-\beta)=g(-1)=0(\because \text { 領域外 }) \\
S_{1}(\beta)=S_{1}(2)
\end{array}\right. \\
& \vdots \\
& \beta=\mathrm{m}-1 \text { とおいて， } \\
& \left\{\begin{array}{l}
g(\alpha-\beta)=g(-m)=0 \\
S_{1}(\beta)=S_{1}(m-1)
\end{array}\right. \\
& \text { したがって， } \\
& C(2)=g(1) S_{1}(0)+g(0) S_{1}(1)+0 \cdot S_{1}(2) \\
& +\cdots \cdots+0 \cdot S_{1}(m-1)
\end{aligned}
$$

同様にして $C(\alpha)$ を順次求めて行くと,

$$
\begin{aligned}
& \alpha=m-1 \text { のとき. } \\
& \beta=0 \text { とおいて, } \\
& \left\{\begin{array}{l}
g(\alpha-\beta)=g(m-1) \\
S_{1}(\beta)=S_{1}(0)
\end{array}\right. \\
& \beta=1 \text { とおいて, } \\
& \left\{\begin{array}{l}
g(\alpha-\beta)=g(m-2) \\
S_{1}(\beta)=S_{1}(1)
\end{array}\right. \\
& \beta=2 \text { とおいて, } \\
& \left\{\begin{array}{l}
g(\alpha-\beta)=g(m-3) \\
S_{1}(\beta)=S_{1}(2)
\end{array}\right. \\
& \vdots \\
& \beta=m-1 \text { とおいて， }
\end{aligned}
$$

$$
\begin{aligned}
& \left\{\begin{array}{l}
g(\alpha-\beta)=g(0) \\
S_{1}(\beta)=S_{1}(m-1)
\end{array}\right. \\
& \text { したがって， } \\
& C(m-1)=g(m-1) S_{1}(0)+g(m-2) S_{1}(1) \\
& +g(m-3) S_{1}(2)+\cdots \cdots+g(0) S_{1}(m-1)
\end{aligned}
$$

以上のことにより, 次のととが言える.

列ベクトル $\boldsymbol{C}$ 扰よび $\boldsymbol{S}_{1}$ ， そして $m \times m$ の正方行列 $\boldsymbol{G}$ を次のごとく定義する.

$$
\begin{aligned}
\boldsymbol{C} & =[C(0), C(1), C(2), \cdots \cdots, C(m-1)]^{T} \\
S_{1} & =\left[S_{1}(0), S_{1}(1), S_{1}(2), \cdots \cdots, S_{1}(m-1)\right]^{T}
\end{aligned}
$$

（但し Tは転置記号）

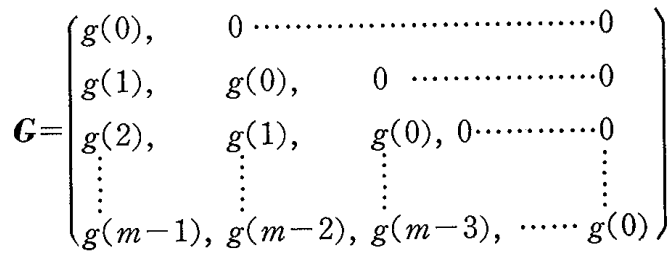

すなわち，(3)式の $\alpha ， \beta$ の変化による，すべての值は，

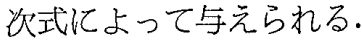

$$
\boldsymbol{C}=\boldsymbol{G} \boldsymbol{S}_{1}
$$

$\boldsymbol{G}$ は, 明らかに, 三角行列であり, 主対角線上の要素 は $g(0)$ と相等しくなっている。

$g(x)$ を空間領域のシステム関数とし， $S_{1}(x)$ を信号の 関数とす机ば, $g(x)$ と $S_{1}(x)$ の重畳積分は，(2)式で表 現され，乙れに対応する行列では主対角線上の要素を等 しくする三角行列と信号ベクトルとの積で表わされる. $\boldsymbol{G} \boldsymbol{S}_{1}$ の存在が空間領域の方から明らかになった。

行列論によれば次のととが定理として存在している. 定理：主対角線上の要素が相等しい，正則対称行列の 逆行列は, 主刘角線上の要素が相等しい, 三角行列と, その転置行列との積で表わされる.

粒状雑音の共分散行列 $\Phi_{n n}$ が，次式によって表わされ るものとする。

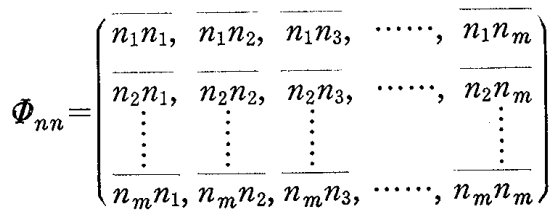

ととろで， $\Phi_{n n}$ の要素に注目すると，Fig. 2 のように， $\overline{n_{i} n_{j}}=\overline{n_{j} n_{i}}$ であり, 各サンプル点における粒状雑音のエ ルゴード性が，放射線面像系沉いいて成立するものとし て $\overline{n_{i} n_{i}}=\sigma^{2}$ と主対角線上の要素を相等しくできる.す ると $\Phi_{n n}$ は, 主対角線上の要素が相等しい正則対称行列 となるので，その逆行列 $\Phi_{n n}^{-1}$ は，主対角線上の要素が相 等しい，三角行列 $\boldsymbol{G}$ とその転置行列との積で表わされ る. 


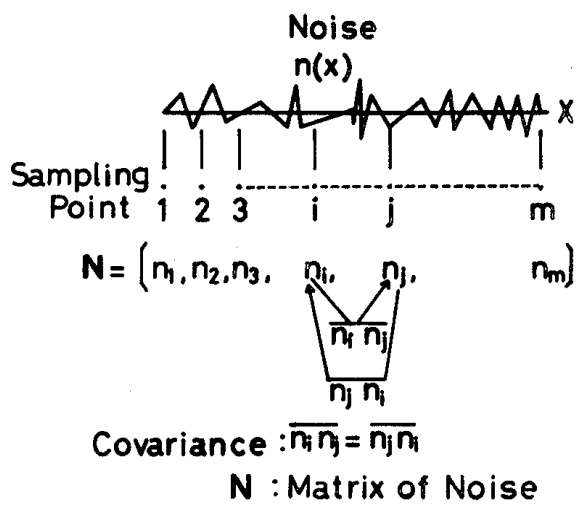

Fig. 2. Mutual relations of matrix elements of the variance and co-variance matrix of noise.

したがって， $\boldsymbol{\Phi}_{n n}^{-1}=\boldsymbol{G}^{\boldsymbol{T}} \boldsymbol{G}$ となり，Gの作用は，有色 雑音を白色化する白色化雑音フィルタとして働く.

すなわち，

$$
\begin{aligned}
\boldsymbol{S}_{1} T \boldsymbol{\Phi}_{n n}^{-1} \boldsymbol{S}_{1} & =\boldsymbol{S}_{1}^{T} \boldsymbol{G}^{T} \boldsymbol{G} \boldsymbol{S}_{1}=\left(\boldsymbol{G} \boldsymbol{S}_{1}\right)^{T}\left(\boldsymbol{G} \boldsymbol{S}_{1}\right) \\
& =\left(\boldsymbol{G} \boldsymbol{S}_{1}\right)^{T} \boldsymbol{E}^{-1}\left(\boldsymbol{G} \boldsymbol{S}_{1}\right)
\end{aligned}
$$

乙とで, $\boldsymbol{E}^{-1}=\boldsymbol{E}, \boldsymbol{E}$ は単位行列で, 白色雑音の共分散 行列を表わす.

\section{3. 結果}

信号の分布関数を $S_{1}(x)$ としそのスペクトルを $S_{1}(u)$, そして信号べクトルを $S_{1}$ とする.

粒状雑音の分布関数を $n(x)$ とし，その自己相関関数 を $\varphi(q)$ ，そのフーリエ変換すなうち粒状雑音のウィナ 一スペクトルを $W(u)$ ，そして粒状雑音の共分散行列を $\Phi_{n n}$ ，その逆行列を $\Phi_{n n}^{-1}$ とすれば， $\Phi_{n n}^{-1}=\boldsymbol{G}^{T} \boldsymbol{G}$ となり， $\boldsymbol{G}$ は, 白色化雑音フィルタで, 主対角線上の要素が相等し い三角行列となる. $\boldsymbol{G}$ 亿刘応するシステム関数 $g(x)$ が考 えられ, 行列 $\boldsymbol{G S}_{1}$ は, $g(x)$ 之 $S_{1}(x)$ との重畳積分 $C(x)$ に対応している. $C(x)$ のフーリェ変換は $G(u) S_{1}(u)$ 之 表わされ， $\Phi_{n n}^{-1}$ が $W(u)^{-1}$ 亿刘応しているので，乙れよ り $G(u)=W(u)^{-1 / 2}$ となる. したがって， $G(u) S_{1}(u)=$ $S_{1}(u) / \sqrt{W(u)}$ と表わされ, スペクトル $S / N$ 比として, 検出能の基本となっている.

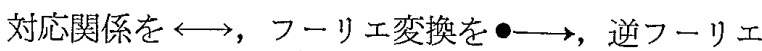
変換を・—↔，そして重畳積分を＊の記号で示すことに する.これをあとにして，

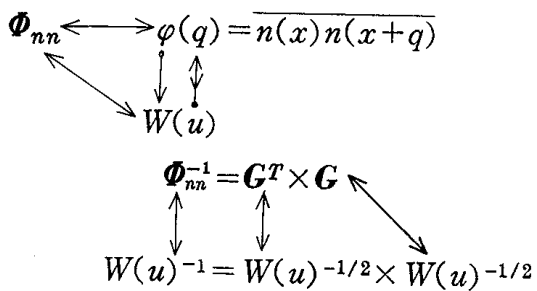

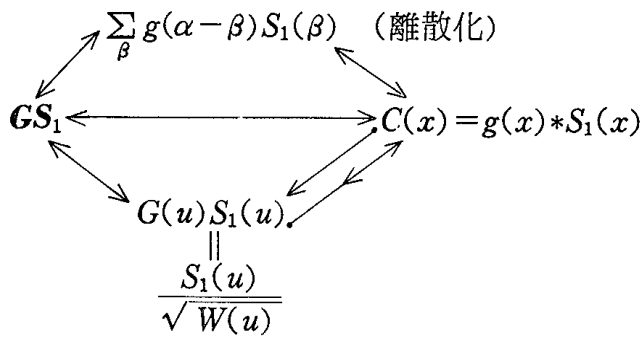

となる。

したがって，検出能 $d^{\prime}$ は，次式となる.

$$
\begin{aligned}
d^{\prime} & =\sqrt{\boldsymbol{S}_{1}{ }^{T} \boldsymbol{\Phi}_{n n}^{-1} \boldsymbol{S}_{1}}=\sqrt{\boldsymbol{S}_{1}{ }^{T} \boldsymbol{G}^{T} \boldsymbol{G} \overline{\boldsymbol{S}_{1}}} \\
& =\sqrt{\left(\boldsymbol{G} \boldsymbol{S}_{1}\right)^{T}\left(\boldsymbol{G} \boldsymbol{S}_{1}\right)}=\sqrt{\int_{-\infty}^{\infty} \frac{S_{1}(u)^{2}}{W(u)} d u}
\end{aligned}
$$

\section{4. 考察}

放射線画像系に求的る粒状雑音の共分散行列の逆行列 が，三角行列とその転置行列との積で表わされることが， 数学的に行列論から証明するととができる. 一方, 三角 行列之信号ベクトルとの積 $\boldsymbol{G} \boldsymbol{S}_{1}$ が白色化雑音フィルタの 空間領域でのシステム関数 $g(x)$ 之信号の分布関数 $S_{1}(x)$ との重畳積分 $C(x)$ に刘応することから, $C(x)$ のフーリ 工変換は, $G(u) S_{1}(u)$ 之なるので, 空間領域 $\rightarrow$ 周波数領 域の立場の屯之に，白色化雑音フィルタの存在が明らか になったすのと考えられる。

逆に，放射線画像系において，粒状雑音のウィナース ペクトル $W(u)$ が存在し, 測定も行われているので, 周 波数領域において，白色化雑音フィルタ関数 $W(u)^{-1 / 2}$ を確かに考えるととができる.すると，行列論より三角行 列が考えられる.このためには，粒状雑音の共分散行列 の逆行列は，正則対称行列でなければならない。したが って， $\Phi_{n n}$ 6正則対称でなければならない。また，逆に， $W(u)^{-1 / 2}$ が存在できるためには， $\boldsymbol{G} \boldsymbol{S}_{1}$ が重畳積分に対 応しなければならない。Ｇは，主対角線上の要素が等し い三角行列となる．したがって $\Phi_{n n}$ は，行列論により主 対角線上の要素が相等しい正則対称行列である. これは 正に，粒状雑音の分散に関するエルゴード性を認めるこ とにほかならない。

$S / N$ 比の表示には, 信号の尖頭値之粒状雑音の RMS 值との此，または信号のエネルギーの平方根と粒状雑音 の RMS 值との比による方法とがあるが，乙れらは，い づれもスペクトル $S / N$ 比 $S_{1}(u) / \sqrt{W(u)}$ をむちいた $S / N$ 比の最大值を与える次式による值を越えることはな い.

$$
\sqrt{\int_{-\infty}^{\infty}\left(\frac{S_{1}(u)}{\sqrt{W(u)}}\right)^{2} d u}=\sqrt[j]{\int_{-\infty}^{\infty} \frac{S_{1}(u)^{2}}{W(u)} d u}
$$

このととは, Schwarz の不等式によってあ遒出される 
あので，検出能 $d^{\prime}$ そのすのが最大の $S / N$ 比を与えてお り, しかも逆に, 検出能をむちいて, Schwarz の不等式 により，理論の結果を従来の $S / N$ 比として表示するて ともできる.すなわち，検出能 $d^{\prime}$ が最も一般的な $S / N$ 比を表わしており，てれが信号および雑音のスペクトル を最むよく反映する $S / N$ 比の表示法であるととは，興 味ある結果であると考えられる。

\section{5. 結語}

検出能は, 白色化雑音フィルタの出力信号のパワーの 平方根で与えられる. 白色化㮠音フィルタの行列は, 三 角行列である。乙れ対応する周波数関数は，W(u $)^{-1 / 2}$ である。

以上の対応か河能になるためには， $\boldsymbol{G} \boldsymbol{S}_{1}$ が重畳積分に 対応しなければならない。そのためには，Gが主対角線 上の要素を相等しくする三角行列であるととになる。し たがって, 結果的に, 粒状雑音の共分散行列が, 主対角 線上の要素を相等しくする正則対称行列でなければなら ない。とれは，雑音の分散に関するエルゴード性を認め るととであり，画像論に対応する分散に関する測定は， ウィナースペクトルが各周波数任亘って充分に収束する ようなデータ数にもとづくあのでなければならない。ま
た，画像論そのものす，精密な物理量の測定を要求する ばかりでなく，測定データを充分に活用包活する方向に 発展さすべきである．てれによって，画像論之物理量の 測定技術の向上が望めるものとなるであるう，白色化雑 音フィルタをむとにして, 多変量密度関数解析による確 率的行列論と周波数解析諭の接点が明らかになった。

\section{文献}

1）若松孝司，山下一也：スペクトル $S / N$ 比を用いた 検出能による総合画像評価の理諭. 日放技学誌， 39 (6), 891-898, (1983).

2) 若松孝司, 伊藤慎三, 今出川和世, 他: スペクトル $S / N$ 比をむちいた，検出能による総合画像評価の増 感紙・フィルム系への応用. 日放技学誌，40(1)， 20-27, (1984).

3）若松孝司：スペクトル $S / N$ 比を用いた檢出能によ る総合画像評価の理論，および増感紙系への応用の 論文汇関する補遺. 日放技学誌，40(2)，(1984).

4）若松孝司：放射線医療画像の解析関する問題点之 その展望 ( $R O C$ 曲線による画像評洒).

5）滝沢英一：情報の理諭と演習. 広川書店，（1968）. 